\title{
Isolation and genetic characterization of enterovirus in patients with febrile rash illness
}

\author{
ZHAOHUI NI ${ }^{*}$, FENGYANG XIANG* ${ }^{*}$, HONGLAN HUANG, GUOQING WANG and FAN LI \\ Department of Pathogenobiology, The Key Laboratory of Zoonosis, Chinese Ministry of Education, \\ College of Basic Medical Science, Jilin University, Changchun, Jilin 130021, P.R. China
}

Received February 3, 2015; Accepted February 26, 2015

DOI: $10.3892 /$ br.2015.441

\begin{abstract}
Measles and rubella virus are usually considered as the causative agents in patients with febrile rash illness (FRI). However, investigators have identified that enteroviruses are also associated with FRI, and the present study was undertaken to investigate this association. In the study, 20 throat swab samples were collected from patients suffering from rash and fever between April and July in 2013. The 20 samples tested negative for measles virus, but all were positive when reverse transcription-polymerase chain reaction was performed using enterovirus universal primers. Specifically, five tested positive for Coxsackie B3 virus (CVB3). The titers of the five CVB3 isolates were $10^{6.5}, 10^{6.4}, 10^{7.5}, 10^{6.5}$ and $10^{6.5}$ tissue culture infectious dose $\mathrm{e}_{50} / 100 \mu \mathrm{l}$ respectively. The partial $V P I$ sequences of the five $C V B 3$ isolates were identical to each other and were closely associated with the CVB3/MKP and CVB3/Macocy strains, which are known to induce myocarditis and neonatal diseases of the central nervous system. In conclusion, CVB3 may cause symptoms of fever and rash and should be differentiated from measles, rubella and other infectious pathogens. The five CVB3 isolates described in the study were genetically similar to each other and to other local CVB3 strains. The results provide further data on the viral pathogen spectrum associated with FRI.
\end{abstract}

Correspondence to: Dr Guoqing Wang or Professor Fan Li, Department of Pathogenobiology, The Key Laboratory of Zoonosis, Chinese Ministry of Education, College of Basic Medical Science, Jilin University, 4026 Yatai Street, Nanguan, Changchun, Jilin 130021, P.R. China

E-mail: qing@jlu.edu.cn

E-mail: lifan@jlu.edu.cn

*Contributed equally

Key words: febrile rash illness, enterrovius, CVB3, VP1, China

\section{Introduction}

Febrile rash illness (FRI) is highly contagious and clinically manifests as fever (temperature $\geq 37.5^{\circ} \mathrm{C}$ ) and a systemic, local skin or mucous membrane rash (1). FRI may be accompanied by other clinical symptoms, such as upper respiratory inflammation, conjunctivitis and systemic mucosal plaques. Viruses associated with FRI include measles (2), rubella (3), enterovirus, varicella-zoster and parvovirus B19 (4). In 1978, China implemented a policy of planned immunization in order to control the incidence of measles. As a result, the incidence of measles has reduced significantly. However, enteroviruses can also cause a similar rash and fever syndrome normally associated with atypical measles. The main enteroviruses include Coxsackie virus A16 and EV71, which cause hand, foot and mouth disease in children. Ju et al (5) reported that the main viruses causing FRI in Guangdong, China between 2010 and 2012 were EV71 and CVA16, accounting for $<82 \%$ of all cases. Coxsackie B3 virus (CVB3) is the main pathogen associated with human viral myocarditis and dilated cardiomyopathy (6). In addition, studies have reported that CVB3 is associated with aseptic meningitis and encephalitis (7) and has also been isolated from patients suffering from hand, foot and mouth disease (8). However, to the best of our knowledge, there are few studies regarding the association between the enterovirus infections, particularly CVB3 infection and FRI. To improve the understanding of the genetic characteristics of enterovirus and its association with RFI in China, a study was conducted of the etiology of fever-rash illnesses in Jilin, China in 2013.

\section{Materials and methods}

Sample processing. Twenty throat swab samples were obtained from the Center for Disease Control and Prevention (CDC) of Jilin, China. Each sample was resuspended in $3 \mathrm{ml}$ of Dulbecco's modified Eagle's medium (DMEM) supplemented with $2 \%$ fetal bovine serum. The samples were subsequently stored at $-80^{\circ} \mathrm{C}$ until further use. Vero cells in DMEM containing $2 \%$ fetal bovine serum were inoculated with $200 \mu \mathrm{l}$ of resuspended sample and incubated at $37^{\circ} \mathrm{C}$ in a $5 \% \mathrm{CO}_{2}$ atmosphere. The cells were observed daily for cytopathic effects (CPE). At least two passages were performed before the culture was regarded as negative for 
Table I. RT-PCR primers.

\begin{tabular}{llc}
\hline Primer & \multicolumn{1}{c}{ Sequence } & Product, bp \\
\hline Enterovirus universal primer & F: CAAGCACTTCTGTTTCCCCGG & 450 \\
& R: ATTGTCACCATAAGCAGCCA & 772 \\
CVB3 specific primer & F: AGGAATTCATGGAAGACGCGATAAC & 211 \\
& R: TGTCTAGATGCTTTGCCTAGTAGTG & \\
EVA16 specific primer & F: TTGCAGACATGATTGACCAG & 226 \\
& R: GAGTGATGGTTCAACACACA & F: GCAGCCCAAAAGAACTTCAC \\
\hline
\end{tabular}

RT-PCR, reverse transcription-polymerase chain reaction; CVB3, Coxsackie B3 virus; bp, base pairs.

Table II. CVB3 sample data.

\begin{tabular}{lcrccc}
\hline No. & Gender & Age & Area & Specimen type & Rash and fever \\
\hline JL-01 & Male & $2 \mathrm{y}$ & Hunchun & Throat swab & Yes \\
JL-02 & Male & $39 \mathrm{y}$ & Tumen & Throat swab & Yes \\
JL-03 & Female & $27 \mathrm{y}$ & Tumen & Throat swab & Yes \\
JL-04 & Male & $4 \mathrm{~m}$ & Dunhua & Throat swab & Yes \\
JL-05 & Male & $1 \mathrm{y}$ & Hunchun & Throat swab & Yes \\
\hline
\end{tabular}

CVB3, Coxsackie B3 virus; m, months; $\mathrm{y}$, years.

CPE. Following complete CPE, the cells were freeze/thawed three times and subsequently centrifuged at 8,000 x $\mathrm{g}$ at $4^{\circ} \mathrm{C}$ for $15 \mathrm{~min}$. The supernatant was collected and stored at $-80^{\circ} \mathrm{C}$.

Viral titer determination. Ten-fold serial dilutions $\left(10^{-1}\right.$ to $\left.10^{-10}\right)$ were made for each virus. Each dilution of virus was inoculated into 8 wells of a 96-well plate containing Vero cells. The plates were incubated at $37^{\circ} \mathrm{C}$ for 7 days. Viral titers were calculated using the Reed-Muench method (9).

RNA extraction, reverse transcription-polymerase chain reaction (RT-PCR) and sequencing. Total RNA was extracted from the infected cell suspension using the Qiagen Viral RNA Mini kit (Qiagen, Hilden, Germany) following the manufacturer's instructions. The extracted RNA was used as a template for RT-PCR amplification using Takara RT-PCR kit version 3.0. The enterovirus universal primers and specific primers of the VP1 genes for CVB3, CVA 16 and EV71 are listed in Table I. RT was performed at $42^{\circ} \mathrm{C}$ for $30 \mathrm{~min}$ followed by a denaturation step at $95^{\circ} \mathrm{C}$ for $5 \mathrm{~min}$. The cycling conditions for enterovirus specific PCR were as follows: Initial denaturation at $94^{\circ} \mathrm{C}$ for $1 \mathrm{~min}, 40$ cycles at $94^{\circ} \mathrm{C}$ for $1 \mathrm{~min}, 50^{\circ} \mathrm{C}$ for $1 \mathrm{~min}$ and $72^{\circ} \mathrm{C}$ for $90 \mathrm{sec}$, and a final extension at $72^{\circ} \mathrm{C}$ for $10 \mathrm{~min}$. The thermocycling conditions for $C V B 3$ were as follows: Initial denaturation at $94^{\circ} \mathrm{C}$ for $2 \mathrm{~min}, 30$ cycles at $94^{\circ} \mathrm{C}$ for $30 \mathrm{sec}$, $55^{\circ} \mathrm{C}$ for $45 \mathrm{sec}$ and $72^{\circ} \mathrm{C}$ for $45 \mathrm{sec}$, and a final elongation step at $72^{\circ} \mathrm{C}$ for $8 \mathrm{~min}$. RT-PCR products were gel purified and sent for sequencing at the Sangon Biotech Institute Co., Ltd. (Shanghai, China).

Data analysis. The GenBank database was searched for similar sequences using the BLAST program. Nucleotide and deduced amino acid sequences of the viruses were aligned using the BioEdit 7.0.5.3 software (10) and subsequently compared with each other and with the reference sequences of homologous $C V B 3$ retrieved from the GenBank database. Phylogenetic trees were generated using Mega 6.0 (11) and the maximum likelihood method and Kimura two-parameter model. Bootstrapping was performed with 1,000 replicates.

\section{Results}

Isolation and virus identification. Twenty throat swabs were collected from patients who presented with symptoms of FRI (temperature $\geq 37.5^{\circ} \mathrm{C}$ and a rash on the face, neck or trunk) between April and June 2013 in three different areas of Jilin, China. All the samples were provided by the Jilin Provincial CDC. The 20 samples were all positive for enterovirus by RT-PCR. When specific primers for $C V B 3$, $C V A 16$ and $E V 71$ were used, only five samples were positive for $C V B 3$. The other 15 samples were negative for these three viruses. Specific details of the five positive samples (JL-01, JL-02, JL-03, JL-04 and JL-05) are shown in Table II.

Virus titers. The titers of JL-01, JL-02, JL-03, JL-04 and JL-05 were $10^{6.5}, 10^{6.4}, 10^{7.5}, 10^{6.5}$ and $10^{6.5}$ tissue culture infectious 


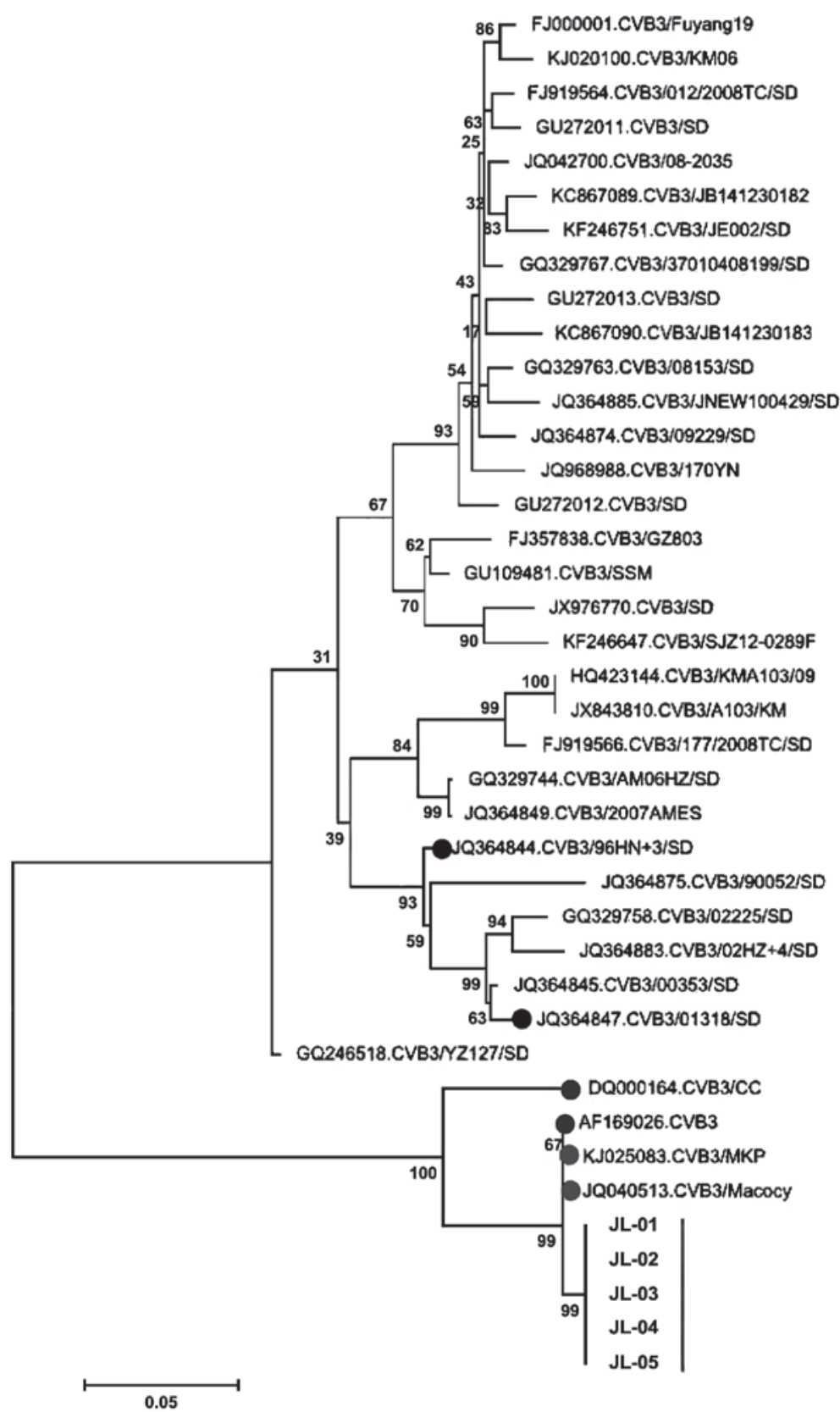

Figure 1. Phylogenetic tree of the $C V B 3$ strains based on partial sequencing of the VP1 gene. All the strains are from different locations in China. $C V B 3$, Coxsackie $\mathrm{B} 3$ virus.

dose $_{50} / 100 \mu 1$, respectively, indicating a strong ability to infect Vero cells.

Sequence analysis of VP1. The amplified VP1 fragments of $C V B 3$ were 772 base pairs. Comparisons of the VPl gene fragments indicated that the five CVB3 viruses were between 99.99-100\% identical at the nucleotide and amino acid levels. In addition, all the isolates were $99.99 \%$ identical at the nucleotide and amino acid levels to the CVB3/MKP and CVB3/Macocy viruses, which have been reported to induce myocarditis and central nervous system disease $(12,13)$, respectively. The phylogenetic analysis using the VPI sequences (Fig. 1) showed that the five CVB3 isolates were genetically distinct from the CVB3/96HN.3/SD (JQ364844) and CVB3/01318/SD (JQ364847) viruses, which have been isolated from Shandong and are known to cause aseptic meningitis (14). DQ000164 and AF169026, which were isolated from Harbin and Beijing in 2005 and 1999, are located on the same branch with the five CVB3 isolates in the present study.

\section{Discussion}

Rash and fever can be caused by infections, allergies and connective tissue diseases. Currently, the primary viruses known to cause rash and fever are measles, varicella, parvovirus B19 and enterovirus. Measles is a highly contagious disease and is often accompanied by serious complications. Since the global implementation of the measles immunization program, the incidence of measles has decreased significantly, while parvovirus B19 infection rates have been increasing. 
The enteroviruses most frequently reported are EV71 and CVA16, which cause hand, foot and mouth disease in children. CVB3 is reported less often, however, it is most often associated with viral myocarditis. With the development of molecular biological techniques, the biology of CVB3 has become clearer (15). However, due to variability in the $C V B 3$ genome, the same serotypes can exhibit differences in virulence and cell tropism (16). The susceptibility and clinical manifestations of different populations to $C V B 3$ can vary. In addition, CVB3 infections are predominantly asymptomatic, so they can be missed or misdiagnosed.

In the present study, 20 samples from individuals suffering from RFI tested negative for measles and positive for enterovirus. Specifically, CVB3 was isolated from five of the samples. The isolates were able to infect Vero cells, indicating pathogenicity (12). Further studies are required to identify the enterovirus(es) present in the remaining 15 samples.

The VP1 region is particularly important in the molecular characterization of enteroviruses. VP1 possesses neutralizing epitopes that directly affect the antigenicity of the virus. By analyzing the $C V B 3 V P 1$ sequence, five CVB3 viruses isolated in the present study were similar to each other and other local Chinese isolates. The homology of nucleotides and amino acids were 99.73-99.99\% and 99.93-99.99\%, respectively, suggesting that the VP1 region of Chinese CVB3 isolates is highly conservative. These results indicate that the CVB3/MKP and CVB3/Macocy viruses, which induce myocarditis and central nervous system disease, respectively, are located in the same clade as the five isolates identified in the present study, suggesting that they may have tropism characteristics for the heart and the central nervous system. However, further studies are required to confirm this observation.

In conclusion, CVB3 may be responsible for RFI. In addition, sequence data was generated for the VPl gene from CVB3 isolates. The present study provides a basis for future research on these viruses in Jilin, China.

\section{Acknowledgements}

The authors would like to thank Dr Jiang Bian from the CDC of Jilin, China, for collecting the samples used in the present study. The study was supported by the National Natural Science Foundation of China (grant nos. 81271897 and 81472662), Foundation of Jilin Provincial Health Department (grant no. 2012Z083) and the Basic Scientific Research Program of Jilin University.

\section{References}

1. de Moraes JC, Toscano CM, de Barros EN, Kemp B, Lievano F, Jacobson S, Afonso AMS, Strebel PM and Cairns KL; VigiFex Group: Etiologies of rash and fever illnesses in Campinas, Brazil. J Infect Dis 204 (Suppl 2): S627-S636, 2011.

2. World Health Organization: Manual for the laboratory diagnosis of measles and rubella virus infection. 2nd edition. Geneva, Switzerland, 2007.

3. Andrus JK and Periago MR: Elimination of rubella and congenital rubella syndrome in the Americas: Another opportunity to address inequities in health. Rev Panam Salud Publica 15: 145-146, 2004.

4. Ramsay M, Reacher M, O'Flynn C, Buttery R, Hadden F, Cohen B, Knowles W, Wreghitt T and Brown D: Causes of morbilliform rash in a highly immunised English population. Arch Dis Child 87: 202-206, 2002.

5. Ju XF, Xu AG, Fang QY and Huang JM: Etiology study on febrile rash illness in Guangdong 2010-2012. Chin J Dis Control Prev ISTIC 17: 670-673, 2013.

6. Fairweather D, Stafford KA and Sung YK: Update on coxsackievirus B3 myocarditis. Curr Opin Rheumatol 24: 401-407, 2012.

7. Tao Z, Wang H, Li Y, Liu G, Xu A, Lin X, Song L, Ji F, Wang S, Cui $\mathrm{N}$, et al: Molecular epidemiology of human enterovirus associated with aseptic meningitis in Shandong Province, China, 2006-2012. PLoS One 9: e89766, 2014.

8. Wong AH, Lau CS, Cheng PK, Ng AY and Lim WW: Coxsackievirus B3-associated aseptic meningitis: An emerging infection in Hong Kong. J Med Virol 83: 483-489, 2011.

9. Reed LJ and Muench H: A simple method of estimating fifty per cent endpoints. Am J Epidemiol 27: 493-497, 1938.

10. Hall TA: BioEdit: A user-friendly biological sequence alignment editor and analysis program for Windows 95/98/NT. Nucl Acids Symp Ser 41: 95-98, 1999.

11. Tamura K, Stecher G, Peterson D, Filipski A and Kumar S: MEGA6: Molecular Evolutionary Genetics Analysis version 6.0. Mol Biol Evol 30: 2725-2729, 2013.

12. Liu B, Li Z, Xiang F, Li F, Zheng Y and Wang G: The whole genome sequence of coxsackievirus B3 MKP strain leading to myocarditis and its molecular phylogenetic analysis. Virol J 11: 33, 2014.

13. Wang L, Dong C, Chen D-E and Song Z: Coxsackievirus-induced acute neonatal central nervous system disease model. Int J Clin Exp Pathol 7: 858-869, 2014.

14. Tao Z, Song Y, Li Y, Liu Y, Jiang P, Lin X, Liu G, Song L, Wang $\mathrm{H}$ and $\mathrm{Xu}$ A: Coxsackievirus B3, Shandong Province, China, 1990-2010. Emerg Infect Dis 18: 1865-1867, 2012.

15. Chapman NM1, Tu Z, Tracy S and Gauntt CJ: An infectious cDNA copy of the genome of a non-cardiovirulent coxsackievirus B3 strain: its complete sequence analysis and comparison to the genomes of cardiovirulent coxsackieviruses. Arch Virol 135: 115-130, 1994.

16. Tu Z, Chapman NM, Hufnagel G, Tracy S, Romero JR, Barry WH, Zhao L, Currey K and Shapiro B: The cardiovirulent phenotype of coxsackievirus B3 is determined at a single site in the genomic 5' nontranslated region. J Virol 69: 4607-4618, 1995. 